\title{
A Violência Conjugal Contra a Mulher a Partir da ótica do Homem Autor da Violência
}

\section{Marital Violence Against Women From the Point of View of the Men Who Were the Aggressors}

\author{
Antonio Gomes da Rosa \\ Mestre em Saúde Pública. Doutorando do Programa de Pós-Gra- \\ duação em Saúde Pública da Universidade Federal de Santa \\ Catarina. \\ Endereço: Campus Universitário, CEP 88040-970, Florianópolis, SC, \\ Brasil. \\ E-mail: angor.blळterra.com.br

\section{Antonio Fernando Boing} \\ Doutor em Odontologia. Professor do Mestrado em Saúde Coletiva \\ da Universidade do Planalto Catarinense. \\ Endereço: Avenida Castelo Branco, 170, CEP 88509-900, Lages, SC, \\ Brasil. \\ E-mail: boingळccs.ufsc.br
}

\section{Fátima Büchele}

Doutora em Enfermagem. Professora do Programa de Pós-Graduação em Saúde Pública da Universidade Federal de Santa Catarina Endereço: Campus Universitário, CEP 88040-970, Florianópolis, SC, Brasil.

E-mail: fbucheleœbrturbo.com.br

\section{Walter Ferreira de Oliveira}

Doutor em Social and Philosophical Foundations of Education. Professor do Programa de Pós-Graduação em Saúde Pública da Universidade Federal de Santa Catarina.

Endereço: Campus Universitário, CEP 88040-970, Florianópolis, SC, Brasil.

E-mail: walter@ccs.ufsc.br

\section{Elza Berger Salema Coelho}

Doutora em Enfermagem. Professora do Programa de Pós-Graduação em Saúde Pública da Universidade Federal de Santa Catarina Endereço: Campus Universitário, CEP 88040-970, Florianópolis, SC, Brasil.

E-mail: elzacoelhoœgmail.com

\section{Resumo}

Este artigo objetiva investigar as causas da agressão conjugal contra a mulher a partir da ótica do homem autor de violência. Para tanto, foi desenvolvida uma pesquisa descritiva exploratória com abordagem qualitativa. Os dados foram coletados por meio da técnica de grupos focais com homens que se envolveram em violência conjugal e participavam voluntariamente do Programa de Atenção à Violência Doméstica e Intrafamiliar de um município de médio porte de Santa Catarina. Na análise das informações, evidenciaram-se três categorias: "Ela", "Eu" e "Outros". Nossos resultados apontam comportamentos e atitudes que permitem identificar as causas da agressão contra a companheira evidenciada a partir da interferência de pessoas estranhas à relação conjugal; presença de ações inadequadas da companheira; domínio da mulher sobre o companheiro; resposta à agressão física, verbal ou psicológica da companheira; dependência química e situação financeira. Os resultados mostram também que essas causas se mesclam no dia-a-dia, acumulamse sob a forma de conflitos e eclodem em atos que configuram a violência conjugal do homem contra a companheira. Os sujeitos da pesquisa não demonstram compreensão ativa de que são agressores, ou seja, reconhecem os atos de violência que relatam, no entanto, não identificam que essas ações os caracterizam como autores de violência.

Palavras-chave: Violência contra a mulher; Violência doméstica; Saúde da mulher. 


\section{Abstract}

This article aims to analyze causes of marital aggression against women from the aggressors' (men) perspective. It is based on an exploratory descriptive study using Focal Groups as a means of collecting information. Research subjects were 11 (eleven) men who had been involved in domestic violence episodes and who voluntarily participated in the Domestic and Intrafamily Violence Assistance Program of a city in Santa Catarina. The analysis of the information yielded three categories: "She", "I" and "Others". The results revealed behaviors and attitudes that allowed to identify the causes that had led the aggressors to attack the partner, such as: strange people's interference in the conjugal relation; presence of partner's inadequate actions; woman's control over the partner; reply to the physical, verbal or psychological aggression of the partner; chemical dependence and financial situation. The results also showed that these causes are mixed in the daily routine, accumulate in the form of conflicts and come out in acts that configure the conjugal violence of the man against the partner. The research subjects do not demonstrate active understanding that they are aggressors, that is, they recognize the violence acts that they report; however, they do not identify that these actions characterize them as aggressors.

Keywords: Violence Against Women; Domestic Violence; Women's Health.

\section{Introdução}

A violência contra a mulher por parte do marido ou parceiro assume números significativos e configurase como relevante problema de saúde pública no Brasil e no mundo. A partir de 48 estudos de base populacional conduzidos em todo o mundo identificou-se que entre $10 \%$ e $69 \%$ das mulheres já foram agredidas pelo seu parceiro (World Health Organization, 2002). No Brasil, pesquisa conduzida em 2001 estima que 2,1 milhões de mulheres já sofreram espancamentos graves, havendo, ainda, uma média de 175 mil mulheres agredidas por mês ou quatro por minuto (Venturi e col., 2001). A violência conjugal representa uma das principais ameaças à saúde das mulheres e a maioria dessas agressões reflete um padrão de abuso contínuo. As conseqüências da violência doméstica para a pessoa agredida são severas e abrangem diversas dimensões, desde ocorrência de fraturas, luxações e hematomas até impactos psicológicos e comportamentais, como depressão, ansiedade, dependência química e farmacológica, ou, em casos mais severos, desequilíbrios que levam a suicídios (World Health Organization, 2002).

A violência entre parceiros engloba comportamentos dentro de uma relação íntima que podem causar morte, lesão, sofrimento físico, sexual ou psicológico e dano moral ou patrimonial (Brasil, 2006). Historicamente, a violência conjugal carrega tabu e medo e em diversos locais não tem sido tratada como crime real, o que acarreta evidente falta de consequências legais a tais atos. Segundo Guattari e Rolnik (1993), o modo como os agressores vivem essa condição de agressor oscila entre dois extremos: uma relação de alienação e de opressão, na qual o homem agressor se submete à subjetividade tal como ela se apresenta; ou uma relação de criação e de expressão, na qual se reapropria dos componentes da subjetividade, criando um processo de singularização, ou seja, reconhecendo as dificuldades que traz consigo e que não dá conta de resolver a não ser por meio da violência.

Para Machado (1998), as estatísticas em torno dos altos índices de violência dos companheiros contra as mulheres no mundo, e mais especificamente no Brasil, não deixam dúvidas quanto à necessidade do seu combate sistematizado, bem como quanto à necessidade de mudanças de comportamento e atitudes do homem e da mulher que vivem juntos e são vítimas e 
autores de violência conjugal. Schraiber e colaboradores (2005) referem pelo menos três razões para trazer a temática de homens e masculinidade para a pauta dos estudos de saúde e gênero. A primeira é por estimular cientistas e formuladores de políticas a enfrentar questões das inter-relações entre os gêneros; em segundo lugar por trazer novas temáticas para os estudos e políticas em saúde da mulher, além de proporcionar novos olhares para antigos objetos da saúde das mulheres e dos homens; e, finalmente, por ressaltar o entrelaçamento entre saúde, cidadania e direitos humanos.

Compreendemos que ainda existem importantes lacunas e dúvidas com relação ao tema violência conjugal. Investigações a partir da visão da pessoa agressora ainda são escassas, no entanto, podem contribuir substancialmente para uma melhor compreensão desse fenômeno e para desvelar nesse universo a percepção de que a agressão exige mais do que a punição prevista em lei, ou seja, é importante que ocorra a instrumentalização de políticas públicas que incluam esse homem e que essa ação possa minimizar a violência praticada contra a mulher. Consideramos que a solução da agressão envolve aspectos complexos que vão além da penalização, uma vez que ela afeta não só o indivíduo e as vítimas diretas, mas também a família e a sociedade como um todo. Assim, este artigo busca identificar causas da agressão conjugal contra a mulher a partir da ótica do homem autor de violência.

\section{Material e Métodos}

Este estudo caracteriza-se como descritivo-exploratório, com abordagem qualitativa, e foi desenvolvido no âmbito de um Programa de Atenção à Violência Doméstica e Intrafamiliar. Esse programa, através de ações socioeducativas, presta atendimento a homens autores de agressões e acompanha mulheres que foram vítimas de violência em um município de Santa Catarina.

O Programa de Prevenção e Combate à Violência Doméstica e Intrafamiliar é mantido pela Secretaria de Assistência Social da Criança e Adolescente do município e tem como objetivo acolher e apoiar famílias, buscando garantir seus direitos e propiciar condições de fortalecimento da auto-estima e autonomia pessoal e social. São disponibilizados atendimentos psicológicos, familiares (casal e/ou filhos), apoio jurí- dico e serviço judiciário, além das reuniões socioeducativas (ação interdisciplinar). Conta, ainda, com o apoio da casa-abrigo, disponibilizada às mulheres que sofrem violência e aos filhos menores de 18 anos com risco à sua integridade física e que não possuam familiares em condições de acolhê-los. Para receber e proteger as mulheres e seus filhos, a casa conta com um gerente de proteção especial, uma coordenadora, cinco orientadoras sociais, uma cozinheira e uma auxiliar de serviços gerais.

Em relação ao atendimento a homens e mulheres pelo Programa de Prevenção e Combate à Violência Doméstica e Intrafamiliar, ocorrem ações socioeducativas realizadas mensalmente e que incluem exercícios de percepção corporal, estudo e troca de experiências, atendimento coletivo e/ou individual e fortalecimento do convívio.

Para a realização do presente estudo, inicialmente expusemos os seus objetivos à coordenação do programa e sua aquiescência foi obtida. Assim, participamos de uma reunião conduzida pela psicóloga do serviço, momento em que convidamos os participantes a se inserirem no nosso estudo como voluntários. Onze homens autores de violência contra suas parceiras aceitaram participar da pesquisa e, para serem obtidos dados detalhados e aprofundados sobre o tema violência conjugal, foram divididos aleatoriamente em dois grupos, um com cinco pessoas e outro com seis. A coleta de dados ocorreu nos meses de outubro e novembro de 2006.

A técnica de grupo focal foi utilizada para coleta dos dados. As entrevistas foram conduzidas por um dos autores deste texto e tiveram duração média, em cada grupo, de aproximadamente uma hora. Sendo as características sociodemográficas dos sujeitos de pesquisa dos dois grupos semelhantes, a mesma técnica foi aplicada, havendo um encontro com cada grupo. Dessa maneira, os dados foram analisados conjuntamente. No início dos encontros foram explicados os objetivos da pesquisa, garantindo aos sujeitos o direito de participar ou não do grupo, e também garantindo o sigilo quanto à sua identidade. A focalização da discussão se configurou a partir da pergunta: "O que te levou a agredir tua companheira?" Os participantes eram assim incentivados a falar, sob sua ótica, sobre os motivos da agressão à companheira e a responder aos comentários dos outros membros do grupo. 
Através da observação participante, característica do grupo focal, foi possível ao pesquisador obter conhecimento direto dos comportamentos, atitudes, linguagem e percepções do grupo. Além disso, as entrevistas focais foram gravadas, transcritas e examinadas. Realizou-se leitura flutuante e identificaramse as categorias a serem investigadas no estudo. A análise dos dados seguiu a orientação proposta por Minayo (1998), compreendendo a ordenação dos dados, a classificação e a análise final.

O presente estudo foi aprovado pelo Comitê de Ética da Universidade Federal de Santa Catarina, sob parecer $n^{\circ}$.221/05.

\section{Resultados e Discussão}

\section{A violência conjugal justificada na fala dos agressores: categorias identificadas}

$\mathrm{Na}$ análise dos dados coletados, a partir da leitura e releitura das falas dos homens autores de violência participantes dos dois grupos focais, evidenciamos, inicialmente, 'quem', segundo os autores da violência, eram os responsáveis pela agressão, o que resultou nas seguintes categorias: ‘Ela', 'Eu' e 'Outros'.

A categoria 'Ela' foi relacionada com a identificação de atitude inadequada por parte da mulher que, segundo o homem, agia de maneira autoritária para com o companheiro. Essa categoria gerou três subcategorias: 'Presença de ações ou atitudes inadequadas da companheira', 'Domínio da mulher sobre o companheiro' e 'Resposta à agressão física, verbal ou psicológica da companheira'.

A categoria 'Eu' evidenciou-se quando o homem agressor explicitava irritação com a companheira e/ ou considerava ofensa quando ela reclamava, geralmente por ele estar bebendo no bar. Essa categoria gerou duas subcategorias: 'Dependência química' e 'Situação financeira'.

Na categoria 'Outros' os sujeitos atribuíram a responsabilidade de suas ações a alguém externo ao casal, levando-os à atitude que se caracterizava como agressão. Por exemplo, quando o sujeito relatava que a discussão ocorria por conta da presença de uma amiga, entendemos que se referia ao 'outro' como desencadeador ou responsável pela agressão. Essa categoria gerou a subcategoria 'Interferências de pessoas alheias à relação conjugal'.

\section{'Ela': Quando o motivo da agressão é atribuído à companheira}

Explícita ou implicitamente, os sujeitos do grupo focal centralizam na companheira o motivo da agressão. Os que se inseriram na subcategoria 'Presença de ações ou atitudes inadequadas da companheira' justificaram que foram as ações dela que levaram o casal à situação caracterizada como violenta. Assim, transferem para a companheira a culpa pela situação, não se reconhecendo como agressores; ao contrário, racionalizam a ação agressiva como comportamento desencadeado pela mulher. Essa atitude vai ao encontro do que descreve Schraiber (2002): o agressor credita o êxito do relacionamento ao comportamento do(a) companheiro(a). Assim, se a relação não dá certo, o motivo é do outro. Para Goleman (2003), a racionalização é uma das estratégias mais comuns de negação dos verdadeiros motivos do sujeito, cobrindo e bloqueando o verdadeiro impulso que provocou o ato agressivo, substituindo-o por outro, inventado.

Um dos motivos de agressão apontado pelos sujeitos é que a companheira não estava tendo com os filhos os cuidados que consideravam adequados, deixando transparecer que essas atitudes, na opinião deles, não deveriam ocorrer, conforme relato a seguir:

Eram duas horas da manhã e eu estava lá na janela, os filhos não tinham vindo. Eu chamava ela, e ela não dava bola [...]; às vezes não cuida muito bem nem dos filhos; os filhos, ela deixava os filhos... à vontade.

Evidenciamos que conflitos frequentes em relação a assuntos familiares, como o cuidar dos filhos, podem ser componentes importantes na gênese da violência doméstica. $O$ cuidado com os filhos pode ser utilizado como desculpa para o homem ou a mulher agredir o(a) companheiro(a) e como justificativa para violência na família (Schraiber, 2002). Para DantasBerger e Giffin (2005), uma ordem social de tradição patriarcal por muito tempo "consentiu" num certo padrão de violência contra mulheres, designando ao homem o papel "ativo" na relação social e sexual entre os sexos, ao mesmo tempo em que restringiu a sexualidade feminina à passividade e à reprodução. Com o domínio econômico do homem enquanto provedor, a dependência financeira feminina parecia explicar a aceitação de seus “deveres conjugais", que incluíam o "serviço sexual”. 
Além de apontar ações inadequadas da companheira enquanto mãe, os sujeitos referiram-se ao 'Domínio da mulher sobre o companheiro', definindo outra subcategoria. Constatamos que os sujeitos mencionaram insistentemente o comportamento dominador da companheira, demonstrando insatisfação com isso e/ ou se sentiam irritados, humilhados e magoados, conforme destacado a seguir:

Ela me incomoda. Às vezes não dá pra aguentar; ela que quer tá certa; ela humilha, magoa a gente. A minha mulher não se preocupa em fazer a comida pra quando eu chego em casa e ainda por cima às vezes quando vou comer se foi ela que comprou me provoca dizendo que eu vou comer a comida dela.

Segundo Ferrari (2002), a necessidade de dominar e controlar o parceiro é a força principal que alimenta a violência entre casais. Esse autor vê a violência dentro da família como um fenômeno multicausal que engloba experiência de socialização, características patológicas, fatores situacionais de estresse e fatores culturais. Esse ponto de vista parece ser ilustrado na colocação que segue:

Ela quer mandar em casa!!! Quer dominar, quer sempre que a gente faça... Seja a perfeição ... o que é a perfeição.... não ir com os amigos depois do trabalho no armazém, não fazer nada.

A violência pode ser pensada do ponto de vista de relações de força expressas enquanto relações de dominação. Nessa ótica, pode-se especular que as diferenças na sociedade são convertidas em relações de desigualdade, que são por sua vez convertidas em relações assimétricas de hierarquia, que implicam em que a vontade de uns seja subordinada a de outros (Ferrari, 2002). Os variados tipos de violência, de acordo com Boulding (1981), se ligam a esta forma de estruturação social e formam uma rede intrincada e complexa em que todos, cada um a seu modo, tornamse ao mesmo tempo vítimas e autores.

Como em uma epidemia, todos são atingidos pela fonte comum de uma estrutura social desigual e injusta, que não só alimenta, mas também mantém ativos os focos específicos de violência que se expressam, inclusive, nas relações conjugais. Esse fato relacionase à violência de gênero, manifestada de maneira perversa a partir das relações de poder historicamente desiguais entre homens e mulheres, sendo o compo- nente cultural seu sustentáculo e fator de perpetuação (Carreira e Pandjiarjian, 2003).

Apesar do crescimento no número de pesquisas sobre violência contra a mulher e das estatísticas já apresentadas, ainda há a dificuldade de se precisar a real magnitude da violência, pois a relação conjugal, a familiar e o ambiente doméstico ainda são considerados aspectos privados e particulares, naturalizando e banalizando este fenômeno social cotidiano. Para Giddens (200o), as relações podem ser ordenadas por meio do diálogo, e não do poder arraigado.

A violência pode também ser vista como uma ação que envolve a perda de autonomia, de forma que as pessoas são privadas de manifestarem sua vontade, submetendo-se à vontade e ao desejo dos outros. Assim, a violência passa a ser utilizada como uma maneira de manifestação das relações de dominação, expressando uma negação da liberdade do outro, da igualdade, da vida. Essa desigualdade se manifesta como assimetria de poder, a submissão do mais fraco pelo mais forte traduzindo-se em maus-tratos (Vecina, 2002).

Os sentimentos expressos pelos sujeitos deste estudo evocam a necessidade de mudanças de comportamento e atitudes de homens e mulheres que convivem em situação de violência conjugal, conforme já apontado por Santana e Ribeiro (200o) e Fukuda e colaboradores (2002). Para esses autores, normalmente ocorrem, ao mesmo tempo, na vida conjugal, vários tipos de violência, às vezes tornando difícil atribuir de forma peremptória os papéis de vítima e algoz. Do ponto de vista do agressor há alternância de papéis, mesclando-se o de agressor (enquanto protagonista na ação agressiva) e o de vítima (ao responsabilizar a mulher quanto à motivação do comportamento agressivo). Camargo (2002) já apontava essa alternância, que descreve o aprisionamento do sujeito nesses dois papéis.

Além de os sujeitos terem mencionado domínio da mulher, afirmaram ainda que ela os agredia verbal ou fisicamente, o que permite evidenciar a subcategoria 'Resposta à agressão física, verbal ou psicológica da companheira'. A agressão decorre de vários motivos, mesmo quando eles não admitem que sejam agressores. Os sujeitos deixaram evidente que "houve uma agressão, sim [...]" e explicam como segue: "ela me avançou. Como é que eu não vou me defender? Ela me avançou com arma, vou me defender [...] empurrei ela em cima da cama, mas não bati nela." 
Durante esse relato do sujeito, observou-se comportamento corporal de suspensão de ombros, talvez sendo colocada uma conotação de justificativa e de naturalidade, como a única atitude a ser tomada, ato complementado pela fala "é... as coisas são assim né!!!". A agressão é assim justificada como ato de legítima defesa; havendo apenas o empurrão e não o espancamento. A minimização e a negação da agressão, por parte dos agressores, são características na dinâmica da violência. O registro a seguir corrobora esta afirmação:

Às vezes com palavras de baixo escalão ela me chateia... [...] acaba agredindo a gente quando não tem dinheiro'; 'ela, às vezes, acaba perdendo o equilibrio e vem agredindo o homem'; 'a própria língua delas desestrutura o homem, daí o cara não tem como, começa a rebaixar, daí vai indo, daí uma hora não tem limite, daí ele já está no ponto';

Às vezes com palavras de baixo escalão ela me chateia... [...] acaba agredindo a gente quando não tem dinheiro;

Ela, às vezes, acaba perdendo o equilibrio e vem agredindo o homem;

Estes relatos chamam a atenção em dois aspectos: primeiro, quando os sujeitos afirmam explicitamente que bateram, deixam subentendido que, nessa situação, a paciência chegou ao limite máximo, criando as condições para a agressão. 0 segundo aspecto é que se usou na narração a primeira pessoa - eu - como participante do fato, mas também se usou a terceira pessoa - ele - como se estivessem falando de outra pessoa. Assim, por vezes colocaram-se como narradores de uma situação vivenciada por outros, o que permite especular que os sujeitos não admitem explicitamente sua condição de agressores.

\section{'Eu': Quando o motivo da agressão é atribuído ao próprio agressor}

Alguns sujeitos, nos grupos focais, mencionaram o uso de 'bebida' em suas vidas, sugerindo que o álcool pode ter contribuído como um dos motivos de desentendimento e/ou agressão. Foi comum o uso de expressões amenizadoras, como 'só uma cervejinha', diminuindo a culpa pela utilização desse elemento. 0 agressor, dessa forma, se expressa através de um filtro que o sustenta dentro de uma racionalização e justifica o meio que utilizou. Como nos alerta Goleman (2003), o agressor tende a ver apenas o que precisa ver, a saber, apenas o que precisa saber, tem consciência apenas daquilo que está preparado para ter. Minayo e Deslades (1998) chamam atenção para o fato de drogas e álcool poderem ser usados tanto antes como depois de eventos violentos.

Sujeitos deste estudo revelaram que "hoje também não bebo mais”, referindo-se à dependência como do passado, definindo-se, assim, a subcategoria 'Hábito de beber'. Em algumas falas a seguir, os sujeitos expuseram que:

eu sou uma pessoa que nunca cheguei... vamos dizer... bêbado em casa; nunca falei, nem mesmo com a esposa... com ela nunca briguei por causa da bebida, teve porque ela não queria que eu bebesse [...] por causa da bebida teve os maiores problemas, entrei em confusão com os empregados, confusão nos bares.

Segundo Dalgalarrondo (200o), o sujeito, ao justificar suas ações sob uma perspectiva simplista e que não lhe pertence mais, pode estar demonstrando, ao mesmo tempo, uma incapacidade de experimentar culpa e de aprender com a experiência, tornando-se vulnerável à reincidência, uma vez que não se diferenciou enquanto sujeito das atitudes que revela.

$\mathrm{O}$ ato de beber foi reconhecido enquanto problema pelos sujeitos dos grupos focais sem, no entanto, relacionarem esse problema às situações de violência com a companheira. Para Minayo e Deslades (1998), o uso de álcool pelo homem mostra-se como um significativo fator de risco para a violência do parceiro contra sua mulher, enquanto para Gomes e colaboradores (2002), o álcool é a substância mais ligada às mudanças de comportamento, provocadas por efeitos psicofarmacológicos que desencadeiam a violência.

Diferentemente da maneira indireta com que os sujeitos relacionaram o álcool com a violência, referiram-se à 'Situação financeira' como causa direta, constituindo-se a subcategoria seguinte a ser analisada. Os desentendimentos surgiram quando:

Ah, ela me disse que eu tinha que trabalhar mais... que faltava coisas em casa... ué, mais ainda?! [...] ela acha que eu sou vadio.

$\varepsilon$ complicado quem tá acostumado a ter e depois não tem como se virar. Daí você é obrigado a dar um jeito, você é o responsável, daí às vezes com 
palavras que parece faca ela leva o homem à loucura... agredindo o homem.

A dificuldade financeira foi claramente colocada como razão de desentendimentos e, portanto, motivo para agressão. Ainda assim, a responsabilização é conferida à mulher, sendo a ação agressiva resultado da interferência da mulher. Morrison e Biehl (200o) afirmam que o baixo nível socioeconômico não é, em essência, causa direta de violência conjugal, mas está associado ao estresse nas relações interpessoais, causado também por outros motivos, como insegurança econômica. Ou seja, frustração e estresse podem ser gatilhos situacionais para o desencadeamento de uma condição psicológica que desestabiliza o homem, propiciando a ação agressiva.

\section{Quando o motivo da agressão é atribuido a 'Outros'}

Para os sujeitos dos grupos focais a interferência de 'outras' pessoas contribuiu sobremaneira para a situação de conflito conjugal. Deixaram transparecer que a situação os incomodava, que os fazia perder o controle sobre si mesmos. Entretanto, alguns sujeitos não admitiram ter agredido a mulher, como segue:

Não cheguei a bater... não... fisicamente... é que a minha mulher escutava muito os outros lá de fora... Daí eu virava num bicho.

Ela não se dá com minha família. [...] depois que ela foi morar com a mãe, daí a gente não conseguia ter aquele diálogo, porque a mãe dela se metia [...] a minha família é que ficou com muita raiva dela e bateram.

Ao indicar que "Ela não se dá com minha família", o sujeito sugere que o problema de relacionamento está com a mulher, e não na família dele. Dalgalarrondo (2000) alerta para a propensão de determinadas pessoas em culpar os outros como forma de explicar seu comportamento. Os sujeitos que reconheceram a situação de conflito conjugal, mas não se reconheceram agressores, tipicamente procuram 'culpados' para a situação. Deslades (1994) nos diz que é comum o agressor se justificar buscando a culpa em outras pessoas. Isto é, de forma consciente ou não, considera que não é culpado pelos acontecimentos, que nada do que acontece está relacionado a ele.

\section{Considerações Finais}

Diante da violência do homem contra a companheira, não há neutralidade possível. É preciso romper o pacto que protege a vazão dos impulsos sob várias justificativas que vão desde uma ofensa à atitude da companheira que ele considera inadequada.

Os sujeitos dos grupos focais apontaram comportamentos e atitudes que sinalizaram para a possibilidade de identificarmos causas da violência conjugal sob a ótica do homem autor da agressão, quais sejam: interferência de pessoas estranhas à relação conjugal; presença de ações e comportamentos inadequados da companheira; domínio da mulher sobre o companheiro; resposta à agressão física, verbal ou psicológica da companheira; hábito de beber e situação financeira. Em relação às causas, constatamos que se mesclam no dia-a-dia, acumulam-se sob a forma de conflitos e eclodem em atos que configuram a violência conjugal do homem contra a companheira. Observamos, ainda, que os sujeitos não demonstraram compreensão ativa de serem agressores, ou seja, ao mesmo tempo em que não negavam os atos que relatavam, não os compreendiam como ações que os caracterizassem como autores da agressão.

Os sujeitos não deixaram transparecer arrependimentos, haja vista a insignificância que deram ao comportamento violento, justificando suas ações como atitudes de defesa ou de reação ao comportamento da companheira, como demonstramos na categoria 'Ela'.

Segundo Gelles (1997), para tratar da violência conjugal é necessário que se adote uma abordagem empática, o que não significa endossar ou minimizar a responsabilidade do agressor, mas significa, sim, compreender o ato violento como resultado de elementos associados à condição do homem autor da agressão.

Os sujeitos tiveram a oportunidade de expressar sentimentos, crenças, justificativas, valores e informações sobre o que os levou a agredir ou, mesmo, a não concordar que agrediram a companheira. Evidenciamos aspectos que consideramos importantes para compreender as causas da violência conjugal, com a finalidade de contribuir com informações sobre o assunto. É preciso que o homem autor da violência não se configure unicamente como caso de polícia, que a Lei Maria da Penha seja efetivamente implementada nos estados e municípios, para que os envolvidos em 
situações de violência sejam institucionalmente acolhidos. E que a sociedade se indigne e assegure à pessoa agredida segurança e dignidade, uma vez que, sozinha, não possui instrumentos capazes de romper com essa realidade para vencer o medo e denunciar as situações de violência.

\section{Referências}

BOULDING, E. Las mujeres y la violencia social. In: UNESCO. La violencia y sus causas. Paris, 1981. p. 265-79.

BRASIL. Lei $\mathrm{n}^{0}$ 11.340, de 7 de agosto de 2006. Cria mecanismos para coibir a violência doméstica e familiar contra a mulher, nos termos do § 80 do art. 226 da Constituição Federal, da Convenção sobre a Eliminação de Todas as Formas de Discriminação contra as Mulheres e da Convenção Interamericana para Prevenir, Punir e Erradicar a Violência contra a Mulher; dispõe sobre a criação dos Juizados de Violência Doméstica e Familiar contra a Mulher; altera o Código de Processo Penal, o Código Penal e a Lei de Execução Penal; e dá outras providências. Diário Oficial da União, Brasília, DF, 8 maio 2006. Seção 1, p. 1.

CAMARGO, C. N. M. F. Agressor ou vítima: a falta básica e as duas faces da mesma moeda. In: FERRARI, D. C. A.; VECINA, T. C. C. (Org.). o fim do silêncio na violência familiar: teoria e prática. São Paulo: Agora, 2002. p.131-140.

CARREIRA, D.; PANDJIARJIAN, V. Vem pra roda! Vem para rede!: guia de apoio à construção de redes de serviços para o enfrentamento da violência contra a mulher. São Paulo: Rede Mulher de Educação, 2003.

DALGALARRONDO, P. Psicopatologia e semiologia dos transtornos mentais. Porto Alegre: Artes Médicas, 2000.

DANTAS-BERGER, S. M.; GIFFIN K. A violência nas relações de conjugalidade: invisibilidade e banalização da violência sexual? Cadernos de Saúde Pública, Rio de Janeiro, v. 21, n. 2, p. 417-425, 2005.

DESLADES, S. F. Prevenir a violência: um desafio para profissionais da saúde. Rio de Janeiro: Centro LatinoAmericano de Estudos de Violência, 1994.
FERRARI, D. C. A. Atendimento psicológico a casos de violência intrafamiliar. In: FERRARI, D. C. A.; VECINA, T. C. C. (Org.). O fim do silêncio na violência familiar: teoria e prática. São Paulo: Agora, 2002. p. 160-173.

FUKUDA, C. C.; RIBEIRO, M. A.; FERRO, V. S. Crianças e adolescentes em situação de risco: quem são suas famílias? In: CONGRESSO BRASILEIRO DE TERAPIA FAMILIAR, V., 2002, Salvador. Anais... Salvador: ABRATEF, 2002. p.18-20.

GELLES, R. J. Intimate violence in families. Beverly Hills: Sage Publicacions, 1997.

\section{GIDDENS, A. Conversas com Anthony Giddens: o} sentido da modernidade. Rio de Janeiro: FGV, 2000.

GOLEMAN, D. Mentiras essenciais, verdades simples: a psicologia da auto-ilusão. Rio de Janeiro: Rocco, 2003.

GOMES, R. A. et al. Por que as crianças são maltratadas?: explicações para a prática de maustratos infantis na literatura. Cadernos de Saúde Pública, Rio de Janeiro, v. 18, n. 3, p. 707-714, 2002.

GUATTARI, F.; ROLNIK, S. Micropolítica: cartografias do desejo. Petrópolis: Vozes, 1993.

MACHADO, L. Z. Matar e morrer no feminino e no masculino. In: OLIVEIRA, D.; GERALDES, E. C.; LIMA, R. B. Primavera já partiu: retratos de homicídios femininos no Brasil. Petrópolis: Vozes, 1998. p. 96121.

MINAYO, M. C. S. (Org.). Pesquisa social: teoria, método e criatividade. Petrópolis: Vozes, 1998.

MINAYO, M. C. S.; DESLADES, S. F. A complexidade das relações entre drogas, álcool e violência. Cadernos de Saúde Pública, Rio de Janeiro, v. 14, n. 1, p. 35-42, 1998.

MORRISON, A. R.; BIEHL, M. L. A família ameaçada: violência doméstica nas Américas. Rio de Janeiro: FGV, 2000.

SANTANA, M. C. P.; RIBEIRO, M. A. A violência intrafamiliar e suas conseqüências no desenvolvimento de crianças e adolescentes. Brasília, DF: UnB, 2000. 
SCHRAIBER, L. B. Violência contra a mulher: estudo em uma unidade de atenção primária à saúde. São Paulo: Departamento de Medicina da USP, 2002.

SCHRAIBER, L. B.; GOMES, R.; COUTO, M. Homens e saúde na pauta da saúde coletiva. Ciência e Saúde Coletiva, Rio de Janeiro, v. 10, n. 1, p. 7-17, 2005.
VECINA, T. C. C. Definição de abuso na infância e na adolescência. In: FERRARI, D. C. A.; VECINA, T. C. C. (Org.). O fim do silêncio na violência familiar: teoria e prática. São Paulo: Agora, 2002. p. 81-94.

VENTURI, G.; RECAMAN, M.; OLIVEIRA, S. A mulher brasileira no espaço público e privado. São Paulo: Fundação Perseu Abramo, 2001.

WORLD HEALTH ORGANIZATION. World report on violence and health. Geneva, 2002. 